\title{
A Review of Employee Turnover Influence Factor and Countermeasure
}

\author{
Yanjuan Zhang \\ School of Management, Jinan University, Guangzhou, China \\ Email: m15622779332@163.com
}

Received 19 May 2016; accepted 6 June 2016; published 9 June 2016

Copyright ( 2016 by author and Scientific Research Publishing Inc.

This work is licensed under the Creative Commons Attribution International License (CC BY). http://creativecommons.org/licenses/by/4.0/

cC) (i) Open Access

\begin{abstract}
Employee turnover is a major field in the study of human resource management. The study is carried out by many Chinese and foreign scholars for a long time, but these studies are only focused on one or two aspects. This article attempts to make a summary on the employee turnover influence factors and puts forward countermeasures from personal factor, organization and work factor, social and economic factor these three aspects. Then we will summary the characteristics of existing studies and put forward the direction of future research.
\end{abstract}

\section{Keywords}

\section{Employee Turnover, Influence Factor, Countermeasure, Review}

\section{Introduction}

Employee turnover is a process of individual who takes the material yield from the organization terminates organization membership [1]. There are advantages and disadvantages for employee turnover. On the one hand, low quality employees can be replaced; the creativity, flexibility and adaptability of organization can be improved. On the other hand, cost of leaving will increase, the cost including explicit cost (recruitment, training, productivity loss, etc.), hidden costs (low morale, reduce enterprise reputation, damage position chain, loss of opportunity, etc.). Generally, employee turnover is grouped into two kinds: voluntary turnover and involuntary turnover. Voluntary turnover refers to decision mainly made by employees leaving the company, including all resignation forms; involuntary turnover refers to the decision of turnover mainly made by the enterprise, including fire, dismiss and other forms. For managers of enterprises, involuntary turnover can be predicted and controlled, but voluntary turnover tends to be unpredictable in advance. The influence of different types of employee turnover for enterprises is different, but too much voluntary turnover is adverse to organization. Therefore, scholars pay more attention to voluntary turnover. This article main discussed voluntary turnover. 
The research history of employee turnover can be traced back to the beginning of the 20th century. The first scholars in the research field of employee turnover is the economist, they mainly stood in a macro perspective to study how wages, labor market structure and the unemployment rate influence employee turnover. Since the 1970s, industrial psychologists studied of employee turnover, they pointed out that there were shortages of economists' study: (1) the range of determinants that used to explain employee turnover was too narrow. It only emphasized the influence of economic factors on employee turnover, and little about non-economic factors; (2) their study was difficult to clarify how decisive influence factors (such as compensation) affected employee turnover. Different from economists, psychologists mainly stood on the micro perspective to study how hidden individual psychology variables influenced on employee turnover, they introduced the concepts that reflected individual different psychological feelings to analyze the decisive factors in employee turnover, and then attempted to describe the process of psychological change of employees making turnover decision. These research perspectives played an important role in open "black box" of employee turnover's psychological motivation [2]. Today, more and more scholars had paid close attention to turnover reason, but these studies only focused on one or two aspects of turnover influence factors. This article tried to research on the influence factor of employee turnover from personal factor, organization and work factor, social and economic factor these three aspects, then systematically summarized countermeasures of employee turnover, finally summed up the characteristics of the existing studies and put forward the future research direction.

\section{Influence Factor of Employee Turnover}

\subsection{Personal Factors}

Individual's own factors mainly include age, gender, education level, marital status, years of working, individual ability, responsibility and so on.

Age, marriage, education levels and years of working in the organization are able to indirectly affect individual turn over intention [3]. Study found that the female employee turnover rate is higher than male employees. It may be connected with women' duty that they need to birth and take care of the family. When employees exist in units or post for a long time, they will feel tired, which can lead to turnover intention. Employees with young, inexperienced and high education level tend to have low level of satisfaction about jobs and careers, and have lower commitment to the organization, these negative attitudes are associated with turnover intention [4]. Individual ability is one of the influence factors of turnover intention [5]. When individuals are not competent at their job, or individuals have strong ability and cannot fully develop in the company, employees are likely to turnover. For employees more than 30 years old, responsibility is one of the important factors for them to leave, the more responsibility (such as staff is the single father or mother, or their income is the main source, etc.) a person bears in the family, the smaller the possibility of his turnover [6].

In short, the individual factors directly affect the turnover and turnover intention, or indirectly influence on them through the regulation of other variables.

\subsection{Organization and Work Factors}

Enterprise culture and system, enterprise benefit and prospect, organization scale, salary, payment and promotion, relationship, training, employee involvement, individual work attitude and organizational justice will influence employee turnover.

Different organizational culture will influence turnover. When a new employee entering into the organization, his individual value orientation and expectation need time break-in with organizational culture and management mechanism. The consistency of personal value orientation and organizational culture can predict employee retention. The higher the consistency, the greater the chance of retention. Employee personal goals and organizational goals fit well can successfully reduce the likelihood of employees leave the organization.

The better the performance of the organization, on the other words, the higher the economic benefits of the organization, the more benefits and advantages can bring to individuals within the organization, such as increasing their income and welfare, the lower incidence of turnover behavior. The better enterprise prospect that employees can observe, the lower the probability of employee turnover [7].

The greater the size of the organization, the stronger the sense of employee security, employees are satisfied and proud of access to the mass organization, generally they do not want to leave the organization. Every em- 
ployee has desire to play a particular character that suits him within the organization, the larger organization size, the more internal opportunities, and more role can be acted, good internal dynamic can improve employee's job satisfaction and reduce turnover behavior. Pursuit of higher income level is the most primitive impulse of employee career. Survey results showed that the industry with low income has higher turnover rate, the personal income level is one of the most important factors. Good employee welfare and reward policy is one aspect of organization commitment, as well as an effective method to reduce employee turnover rate. Personal development opportunities provided by organization is inversely proportion to the employee turnover rate [8].

Interpersonal relationship of company or department has a significant impact on employee turnover intention. When a company or department with complicated interpersonal relationship, there are many factions or small groups, employees are very difficult to deal with the relationship with colleagues and boss, or the employees need to spend a lot of energy to handle in the relationships within the company or department, they will most likely generate turnover intention.

Whether the company can provide training and learning opportunities for staff will also have significant effects on whether employees staying in the group. Employees always have ideal and ambition, if the company cannot give them the opportunity to learn, they cannot improve their abilities, cannot continue to grow, so that employees cannot even get self-realization in the company, they are likely to turnover [9]. The participation degree of company or department decision also positively influences the level of job satisfaction, in turn, directly or indirectly affect turnover intention.

Individual work attitude in the organization including job satisfaction, organizational commitment, job stress, job attitude, there are negative correlation between them and turnover [10]. Job satisfaction and organizational commitment can be influenced by factors such as institutional constraints and the superior behavior, then affect employee turnover. Whether easy to get a new job plays a regulation action on turnover [11]. Application justice and allocation justice will affect the employee attitude, indirect effecting turnover. In addition, position, departure times, working conditions and other factors affect organizational commitment, then influence employee turnover [12]. Switching cost has a significant negative correlation with turnover. Material and spiritual loss due to the change of unit have relations with employees' turnover intention [13].

\subsection{Social and Economic Factors}

Society's economic development level, labor market condition, employment system, job opportunities, enterprise property, transportation, housing, education and health care facilities, the cost of living, quality of life and so on all have an impact on employee's turnover intention [14].

Economic development well, industry personnel in short supply, employment situation relatively good, or job opportunities increase will lead to employee turnover intention. The nature of Chinese enterprises affects employee's turnover intention. Employees in state-owned enterprise have the highest quit intention, second is employees in private enterprises, the last is employees in foreign-funded enterprise. But generally employee in these three types enterprise have high turnover intention, more than the average [15]. Transportation, housing, education and medical facilities are negatively related to the employee turnover to a certain extent. Under the condition of high cost of living, in order to make a living, the probability of employee turnover will reduce. In pursuit of a better quality of life, the staff may choose to give up the current job for higher paying job.

\section{Countermeasure}

In order to solve the problem of employee turnover, enterprises can adopt the following countermeasures.

\subsection{Employee Personal Management}

\subsubsection{Improving Employee Engagement and Achievement in Work by Optimizing Job Design}

By optimizing job design, employees can feel a sense of achievement, so as to reduce the turnover rate [16]. We can take the following three measures to design job: job rotation, job enlargement, job enrichment. When employees are more skilled for a job, increase his workload, accordingly improve treatment at the same time, this will give employees a greater sense of accomplishment. Giving employees a right position that making full use of talents, so as to improve the employee's job satisfaction, then employees will have more job satisfaction [17]. 


\subsubsection{Using Interview, Questionnaire and Observation Method to Understand the Real Inner Needs} of the Staff

To understand the unique, really demand of talents is the basis of retaining talent. Therefore, managers should take various effective ways to really understand the employees' needs, objective and initiative monitor staff performance, carefully listen to employees' conversation, avoiding subjective psychological deviation, so that you can take useful retention measures.

\subsubsection{Dealing with Employee Complaints by Establishing Employee Communication and Feedback Mechanism}

There are both objective reasons (such as bad corporate culture, unclear responsibilities, personal ability cannot play) and subjective reasons (such as arrogance, emotional transformation, unreasonable demands are not met) for the generation of complaint. When Employees complaining, they may have some abnormal phenomenon in the words and deeds, manager must pay attention to the staff's words and deeds, observe the subordinate work attitude and state of mind to realize and deal complaints as early as possible in order to kill turnover inducement in the bud. By setting up a suggestion box and opening BBS, let employees' complaints have a reasonable and smooth feedback approach, along with some propaganda work, deal with complaints soon as possible, to minimize the negative influence of employee, so as to improve the staff's working efficiency, reduce staff turnover rate.

\subsubsection{Making a Fair and Competitive Compensation Benefit, Establishing an Effective Incentive Mechanism}

Employees who worked in the company, hope to get a fair return. Employees on the basis of different capacity, contribution and revenue should have differences, but the income gap must be fair and reasonable. Enterprises must establish fair, just, reasonable and transparent compensation system and performance evaluation system, set up salary structure including basic wage (including post salary, seniority, salary increase, etc.), performance salary, overtime pay and welfare, at the same time, through right post evaluation, salary investigation, fair performance evaluation to ensure the successful implementation and operation of this system. Enterprises should also make benefit plan according to different level staffs' fond and demand, effectively motivate all levels employees. Reasonable compensation system will be good internal incentive mechanism.

\subsubsection{Establishing Perfect Training and Career Development System}

Training is the best reward that the enterprise give to employees, is also a kind of welfare of employees. At the same time, training is an important premise of staff promotion and self-development. In modern society, science and technology develop rapidly, the renewal speed of knowledge and skills is very fast, staff work in a company, not only want material returns, but also hope they can get better sustainable development. Enterprises that cannot improve employees' skills and abilities or cannot provide sustainable development opportunities for employees is difficult to keep good employees for a long time, enterprises should establish career management system, both have the organization career management system and individual career management system, so that enterprises and employees can get long-term development and realize' win-win' between organization and individual. Enterprises should establish a career path for employees, make specialist tailor-made program in view of their talents and personality to meet the needs of the work, to help employees to give full play to their potential and reach the peak of their career. Enterprises can build dual career path for technical staff, provide a technical promotion path for technology workers, improve their status, and accordingly improve their welfare and treatment, make the technical personnel and management personnel have a way of promotion at the same time, thus retaining good technical personnel [18].

\subsubsection{Improving Enterprise and Employee Benefits, as Well as the Working and Living Conditions of the Staff}

Enterprises should not only to improve the overall efficiency, but also want to improve the staff's personal benefits, improve the working and living conditions of the staff, so as to improve the work efficiency of employees. For example, providing shuttle bus or traffic subsidies for employees who live far away from the office, providing ten minutes in the morning and afternoon for employees to rest. 


\subsection{Organizational Management}

\subsubsection{Constructing Excellent Enterprise Culture}

Enterprise culture is fundamental to retain talent. Create a people-oriented corporate culture, regard people as a key object of management and the most important and most creative resources of enterprises, pay attention to the staff, care about them, respect them, trust them, fully empower to them, give them opportunities to independently complete work. Enterprises should cultivate the creativity, participation and cooperation spirit of employees, build the unique and excellent corporate culture is the highest state of retention.

\subsubsection{Coordinating the Relationship of Different Employees and Departments}

To prevent internal factional fighting, enterprises should prevent cliques in department or executive, enterprises should actively advocates corporate culture of integrity. Within the company, build the atmosphere of mutual understanding, respecting and helping between leader-member, colleagues and departments. Employees could dispute because of work problems, but cannot play politics, intrigue, frame and crowd out for personal problems or their own advantages, otherwise, employees will concentrate on the company's interpersonal relationships but ignore their work. In the long term, it will make the employees work efficiency drops, to make the matter worse, it will eventually lead employees turnover. To properly handle internal informal groups, and guide informal groups, give full play to the positive influence of the informal groups, weaken their negative effects. Dealing with the relationships within an enterprise, reduce unnecessary turnover factors.

\subsubsection{Establishing Management Mechanism to Prevent Key Brain Drain}

For an enterprise, if excellent employee who masters the key techniques or confidential enter to rival camps, or set up his own enterprise, the consequences could be disastrous. Therefore, enterprises must establish management mechanism to prevent the key brain drain. First, enterprises should establish personnel information system, including on-the-job personnel information, employee information, talent reserves information, dynamic tracing information of employees' work. Using this system to timely understand the staff's ideological trend, especially in cultivating and promoting key talent, must examine their loyalty to the enterprise. Second, it is to set clear system, regulate key employees cannot work or service enterprises that have interest conflict with the company in a certain period of time, and they should sign a confidentiality contract. This is not only good for restrict employees, but also for enterprises to sue employees for job-hopping. Third is to perfect the content and projects of the incentives for knowledge workers according to the earlier stated incentive principle. Fourth is to do a good job of backup talents so that new product development and market development will not be interrupted by the loss of key knowledgeable employees. Fifth is to establish the responsibility system of labor division. For positions and departments that master a large number of customers and business information, enterprises shall establish a job sharing mechanism that mutual supervision and restraint, and enterprises should in charge of the most important parts of accessing to customers and key business.

\section{Conclusions}

Employee turnover is an important field in the research of human resource management, this article summarizes the current research results from personal factor, organization and work factor, social and economic factor these three aspects that help others who are interested in employee turnover influence factors have a comprehensive understanding. At the same time, this article puts forward countermeasures which help enterprises to deal with this problem. The characteristics of the current research status and some future research directions are as follows.

\subsection{Characteristics of the Research Status}

The characteristics of the current studies are as follows.

Firstly, in general, there are two trends of the turnover study: generalization and elaboration. Generalization reflects in comprehensive discussing influence factors, such as Youxuan Feng researched employee's turnover reason from individual factor, organizational factor, individual-organization fit factor, external environment factor for these four aspects. Elaboration refers to a further study of one influence factor. Such as ZhongminWang studied how several organizational factors influenced on employee turnover. Rensun Ye studied how job 
satisfaction and organizational commitment influenced on employee turnover of state-owned enterprises.

Secondly, the study of turnover, especially empirical research, there are more in abroad than in China, especially in recent years.

Thirdly, previous studies mainly focus on the influence factors of turnover, but the study of turnover moderator variables is not much.

Finally, subjects of the empirical study mostly concentrated in an industry, and samples are small (generally around 200), studies do not establish a general model of turnover. Therefore, although the conclusions have strong applicability, but its theoretical value and generalization are limited.

\subsection{Prospects}

There are many areas of future research that can be found from current studies.

Firstly, the future research of employee turnover influence factor should strengthen the discussion about the effect of a single variable under the condition of controlling a variable, or study the interaction between two or more variables, on the other words; we should pay more attention on the internal psychological process [19].

Furthermore, there should be more empirical research, we should try to choose large sample, and the sample must be representative, combing theory with practice to make the results more convincing.

Finally, we should also pay attention to the role of regulating factors (such as individual psychology and the external environment support, individual economic bearing, organizational support, etc.) in the study of turnover influence factor [20].

\section{References}

[1] Zhang, M. and Li, S.Z. (2002) A Review of Psychological Casual Models of Employee Voluntary Turnover. Journal of Developments in Psychological, 3, 330-341.

[2] Zhang, M. and Zhang, D. (2003) New Process of Foreign Employees Voluntary Turnover Model Research. Foreign Economy and Management, 9, 24-28.

[3] Liu, Y.A. and Wang, F. (2006) A Study on the Influence Factors of Employee Turnover Intention. Enterprise Economy, 6, 42-44.

[4] Ma, S.J., Chen, J.Q. and Wang, L. (2003) A Study on the Causes of Employee Turnover. China Human Resources Development, 9, 18-20.

[5] Chen, B.H. and Li, Q. (1998) A Research Review of Turnover Problem. Journal of Psychology, 1,27-32.

[6] Zhang, M. and Zhang, D. (2003) A Study on the Factors Influencing Voluntary Turnover in IT Companies. China Soft Science, 5, 76-80.

[7] Ling, W.Q., Fang, L.L. and Fu, Y.Q. (2005) The Study on the Effecting Factors and the Accommodating Factors of Chinese Enterprise Employees’ Turnover Intention. Journal of Xiangtan University (Philosophy and Social Sciences Edition), 4, 65-69.

[8] Wang, Z.M., Chen, J.X. and Xu, J.L. (2001) Discuss on Some Organizational Factors of Influencing Employee Turnover. Modernization of Management, 5, 44-46.

[9] Liu, Z.Q., Liu, J.Q. and Li, Z. (2006) The Analysis of Key Influence Factors on Voluntary Turnover Intention of Staff. Journal of Industrial Engineering and Engineering Management, 4, 142-145.

[10] Zhang, M., Zhang, D. and Li, S.Z. (2003) An Empirical Study on a Path Model of Turnover Intention among Technical Staff in IT Enterprises. Nankai Business Review, 4, 12-20.

[11] Ye, R.S., Wang, Y.Q. and Lin, Z.Y.(2005) An Empirical Study of Job Satisfaction and Organizational Commitment Affect Turnover among Employee in State-Owned Enterprises. Management World, 3, 122-125.

[12] Cui, X. (2003) The Empirical Analysis on the Relationship between Individual's Characteristics, Organizational Commitment and Employee Turnover Intention. Nankai Management Review, 4, 4-11.

[13] Zhang, M. and Zhang, D. (2007) The Influence Factors of Employee Turnover Intention: The Quantitative Study of Some New Variables. Management Review, 4, 23-28.

[14] Huang, P.L. and Huang, Z.L. (2006) A Review of Influence Factors of Employee Turnover Intention. Science and Technology Management Research, 5, 153-155.

[15] Zhao, X.P., Liu, L. and Zhang, C.Z. (2003) A Multi-Variable Analysis on Factors Influencing Employee’s Turnover Intention. China Soft Science, 3, 71-74.

[16] Feng, Y.X. and Dai, L.T. (2005) The Analysis on the Factors Affecting Enterprise Staff's Resignation and the Corres- 
ponding Management Tactics. Commercial Research, 5, 60-63.

[17] Li, J.Q. (2003) On the Reason and Countermeasures of Employee Quit from Enterprises. Journal of Southern Yangtze University (Humanities \& Social Edition), 4, 62-64.

[18] Han, Y. and Liao, J.Q. (2007) An Empirical Study on Influencing Factors of Employee Turnover. Economic Management in China, 11, 60-65.

[19] Yang, C.J., Ma, Q.H. and Zeng, X.F. (2010) Job Embeddedness: A New Perspective to Predict Voluntary Turnover. Nankai Business Review, 2, 105-118.

[20] Liu, J., Liu, X.Y. and Ren, B. (2007) Employees’ Resignation: A Longitudinal Study within the Framework of Employment Relationship. Management World, 12, 88-95. 